\title{
Editorial
}

\section{The Removal of $\beta 2$-Microglobulin in Spent Dialysate Cannot Be Monitored by Spectrophotometric Analysis}

\author{
Carlo Donadio $^{a}$ Dario Calia $^{b}$ Silvia Ghimenti ${ }^{b}$ Massimo Onor ${ }^{c}$ \\ Elisa Colombini $^{\mathrm{a}}$ Roger Fuoco $^{\mathrm{b}}$ Fabio Di Francesco ${ }^{\mathrm{b}}$ \\ aDipartimento di Medicina Clinica e Sperimentale, Divisione di Nefrologia, Università di Pisa, ${ }^{b}$ Dipartimento di \\ Chimica e Chimica Industriale, Università di Pisa, and ' Istituto di Chimica dei Composti Organometallici, CNR, \\ Pisa, Italy
}

Toxins are removed from plasma and filtered into the spent dialysate or ultra-filtrate, via diffusion and convection, or trapped inside the membrane by adsorption. It has been already demonstrated that the analysis of spent dialysate by spectrophotometry allows the monitoring of dialysis removal of small molecules and the noninvasive assessment of dialysis efficiency and $\mathrm{Kt} / \mathrm{V}$ [1-5]. The removal of $\beta 2$-microglobulin ( $\beta 2 \mathrm{M}$, MW $11.8 \mathrm{kDa}$ ) from plasma is considered an effective marker of the dialyzer clearance for 'middle molecules' and proteins with molecular weight ranging $10-30 \mathrm{kDa}[6]$.

An interesting paper published in this issue of blood purification by Fredrik Uhlin et al. deals with the possibility to evaluate $\beta 2 \mathrm{M}$ elimination by monitoring the ultraviolet absorbance of spent dialysate. A high correlation was found between UV absorbance and $\beta 2 \mathrm{M}$ during HDF treatment but not for high-flux HD treatments. The authors conclude that UV absorbance could perhaps be used in solely HDF mode for the estimation of $\beta 2 \mathrm{M}$ removal, and that in any case, the possibility of optical estimation of $\beta 2 \mathrm{M}$ must be validated.

We synthetically present here unpublished results on $\beta 2 \mathrm{M}$ removal during HD treatments with dialysis membranes having different flux and adsorption capacities to clarify if the spectrophotometric analysis of spent dialysate may allow the possibility to monitor the removal of $\beta 2 \mathrm{M}$ during HD. These results were obtained from the analyses of serum and spent dialysate samples of the 22 MHD patients (16 men, 6 women) of a previous study, where we confirmed the possibility to monitor the removal of small molecules, namely uric acid, by spectrophotometric analysis (J Nephrol).

Serum and spent dialysate concentrations of $\beta 2 \mathrm{M}$ were measured with an immunonephelometric method (Siemens, BNAII) and compared with absorbance and fluorescence values. The sampling protocol, the analytical procedure, the instrumentation and the statistical methods have been previously described [5].

\section{Absorbance and Fluorescence Spectra of B2-Microglobulin}

In the range $200-600 \mathrm{~nm}, \beta 2 \mathrm{M}$ shows an absorption peak at $280 \mathrm{~nm}$ (fig. 1a). The absorption peaks of urea, creatinine and uric acid are also shown for comparison (fig. 1a). An emission peak at $340 \mathrm{~nm}$ was observed in the fluorescence spectrum of $\beta 2 \mathrm{M}$ in the range $230-510 \mathrm{~nm}$

\section{KARGER 125}

(c) 2015 S. Karger AG, Base

0253-5068/15/0402-0109\$39.50/0 


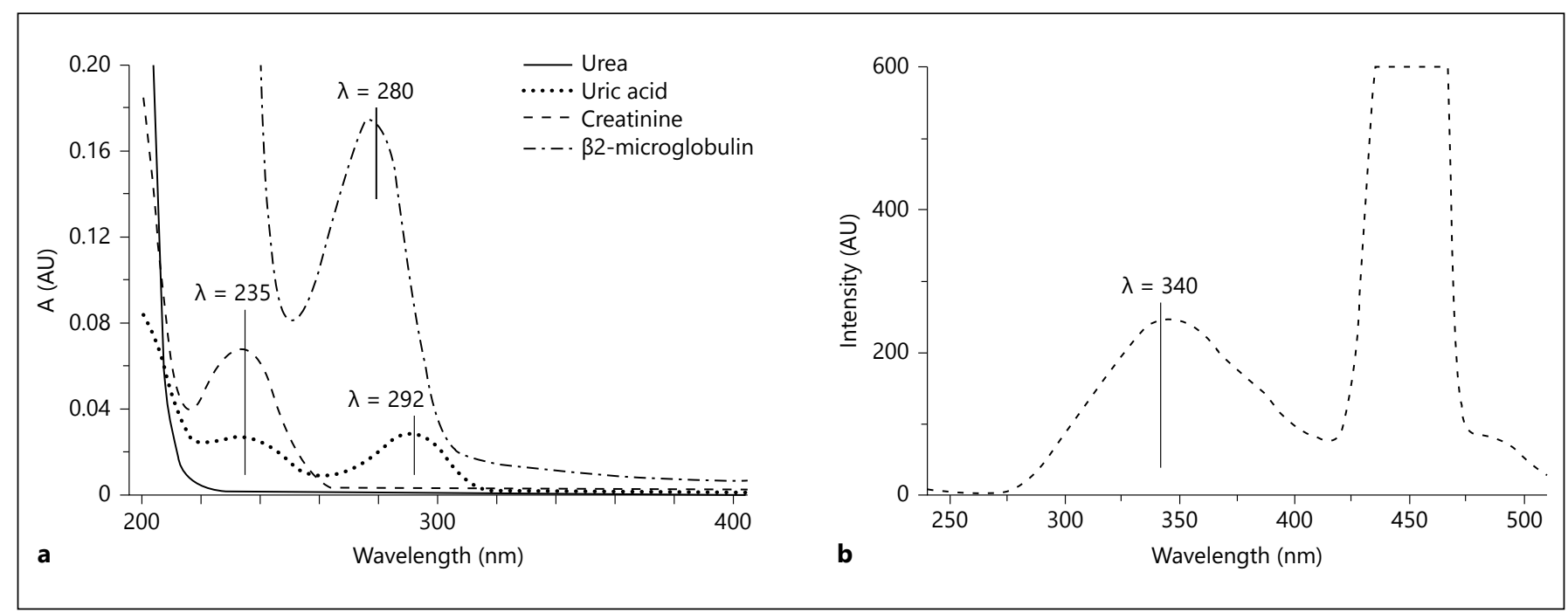

Fig. 1. Absorption (a) and fluorescence spectra (b) of $\beta 2 \mathrm{M}$ (dashdotted line). The absorption spectra of urea (continuous line), uric acid (dotted line), creatinine (dashed line) are reported for com-

(excitation wavelength $220 \mathrm{~nm}$ ) (fig. 1b). On the basis of these data, the UV absorbance was measured at $280 \mathrm{~nm}$, and the fluorescence emission at $340 \mathrm{~nm}$ (excitation wavelength $220 \mathrm{~nm}$ ).

\section{Serum and Spent Dialysate Concentrations, Absorbance and Fluorescence Values in Spent Dialysate Over Time}

During the dialysis sessions with polysulfone low-flux (LF) membrane, $\beta 2 \mathrm{M}$ concentration showed a slight increase in serum (table 1; fig. 2, left). No detectable concentrations of $\beta 2 \mathrm{M}$ were observed in spent dialysate, since this molecule is not cleared from blood by LF membranes. Surprisingly, both UV absorbance at $280 \mathrm{~nm}$ and fluorescence emission at $340 \mathrm{~nm}$ decreased in spent dialysate samples according to exponential functions. During the dialysis sessions with the HF membrane (table 1; fig. 2, middle), the serum and spent dialysate absorbance at $280 \mathrm{~nm}$ showed similar exponential decreases over time, which were much faster than that observed for the fluorescence emission at $340 \mathrm{~nm}$. During treatments with the high-flux and adsorption (HF-ADS) membranes, which has additional adsorption properties, serum $\beta 2 \mathrm{M}$ decreased according to an exponential function (table 1; fig. 2, right), whereas the concentrations in spent dialysate samples had an irregular time course, probably due to absorption into the membrane. The variations of spec- parison. The wavelengths of $\beta 2 \mathrm{M}(280 \mathrm{~nm})$, creatinine $(235 \mathrm{~nm})$, and uric acid ( 235 and $292 \mathrm{~nm}$ ) absorption peaks as well as the $\beta 2 \mathrm{M}$ fluorescence emission peak $(340 \mathrm{~nm})$ are highlighted.

trophotometric signals (absorbance at $280 \mathrm{~nm}$ and fluorescence at $340 \mathrm{~nm}$ ) in spent dialysate over time were completely independent from $\beta 2 \mathrm{M}$ concentrations in dialysate.

\section{The Contribution of $\beta 2$-Microglobulin to UV Absorption and Fluorescence Signals Was Insignificant}

Indeed, in dialysate samples $(\mathrm{n}=86)$ obtained during treatment with HF membranes, the contribution of $\beta 2 \mathrm{M}$ to the absorbance measured at $280 \mathrm{~nm}$ and to the fluorescence at $340 \mathrm{~nm}$ was lower than $0.2 \%$.

All these data indicate that the removal of $\beta 2 \mathrm{M}$ in spent dialysate may be hardly assessed under the experimental conditions used by absorbance or fluorescence measurements, even if $\beta 2 \mathrm{M}$ has an absorption peak at $280 \mathrm{~nm}$ and a fluorescence emission at $340 \mathrm{~nm}$. Indeed, the absorbance peak found for $\beta 2 \mathrm{M}$ at $280 \mathrm{~nm}$ is the same as the one that is currently used to evaluate the removal of small molecules. Furthermore, the contribution of $\beta 2 \mathrm{M}$ to the absorbance was relatively less and its contribution to fluorescence was absolutely negligible. Thus, the absorbance at $280 \mathrm{~nm}$ is mainly due to other substances, namely, uric acid [5]. In fact, significant UV absorption and fluorescence emission signals were also measured treatments with the LF membrane, which do not allow any $\beta 2 \mathrm{M}$ transfer, as demonstrated by the absence 

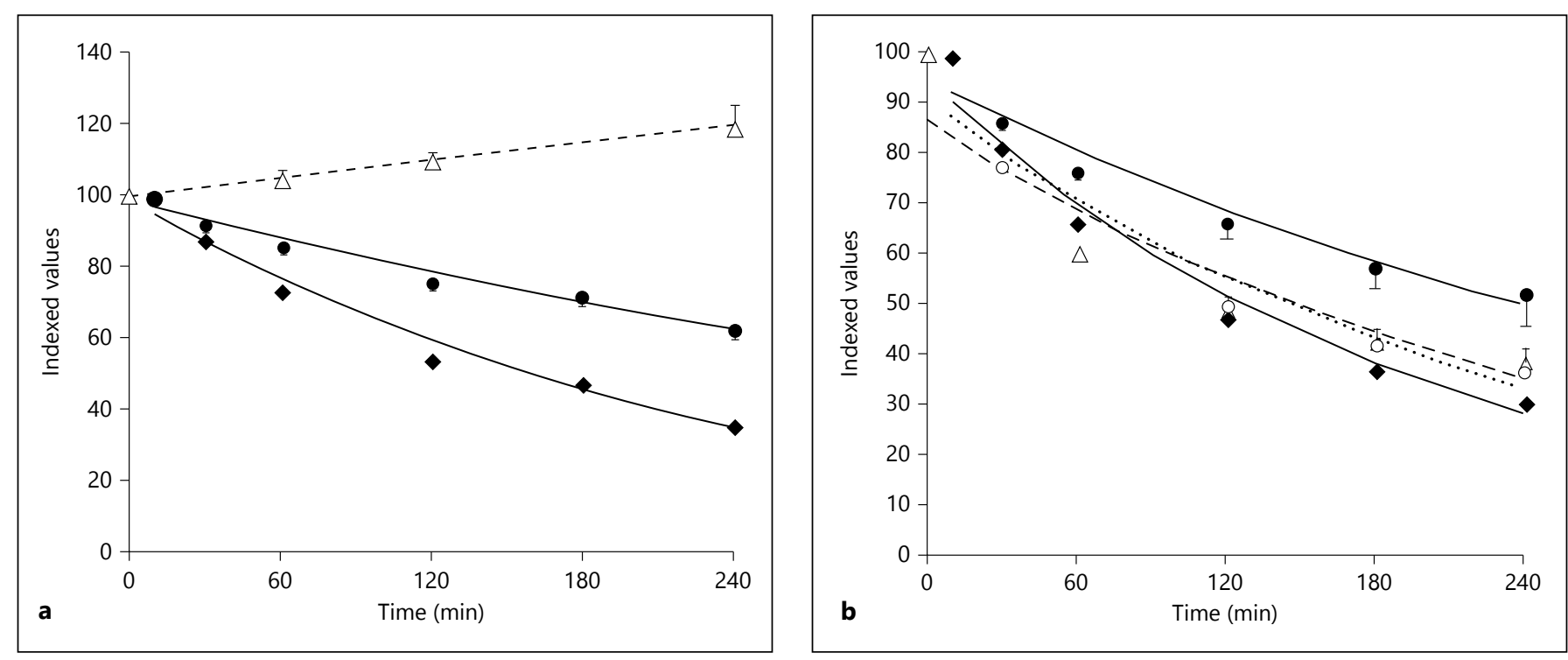

Fig. 2. Serum $(\triangle)$ and spent dialysate $(O)$ concentrations of $\beta 2 \mathrm{M}$ over time compared with absorbance $(\bullet)$ at $280 \mathrm{~nm}$ and fluorescence emission ( ) at $340 \mathrm{~nm}$ in spent dialysate. Values are scaled to maximum (time $0 \mathrm{~min}$ for serum; time $10 \mathrm{~min}$ for spent dialysate); at each time, mean values \pm standard error of the mean are reported. The first plot (a) shows the results in the 11 patients treated with LF membrane; the second plot (b) the results in the 8 patients treated with HF membrane, and the third plot (c) the results in the 3 patients treated with HF membrane with adsorption properties. Correlation coefficients and regression equations are reported in table 1.

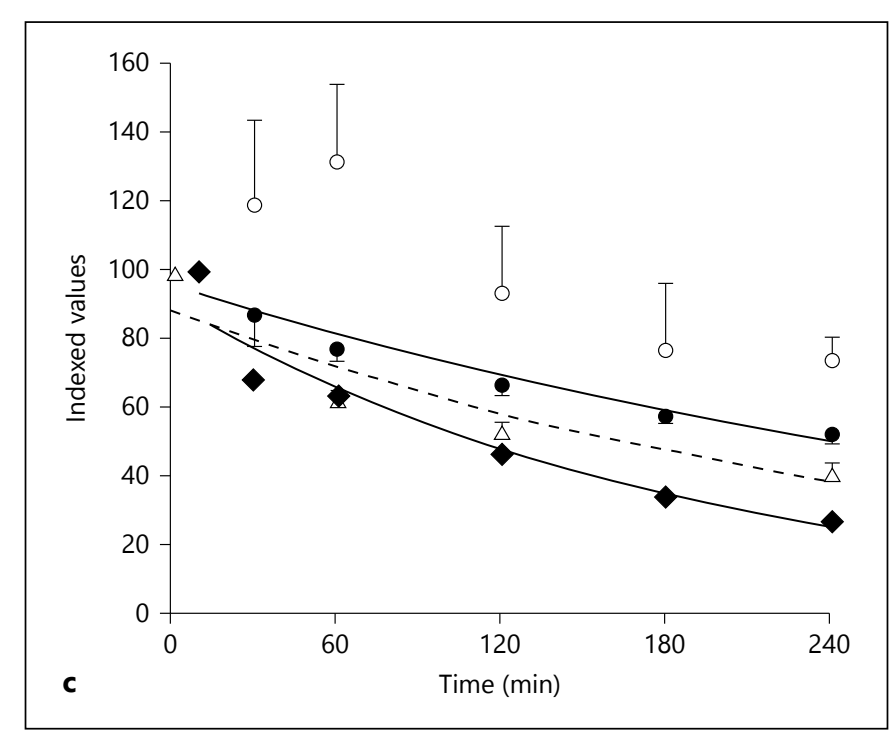

Table 1. Correlation coefficients and regression equations of serum and spent dialysate concentrations of $\beta 2 \mathrm{M}$ over time, compared with absorbance at $280 \mathrm{~nm}$ and fluorescence emission at $340 \mathrm{~nm}$ in spent dialysate

\begin{tabular}{|c|c|c|c|}
\hline & LF membrane & HF membrane & HF-ADS membrane \\
\hline \multicolumn{4}{|l|}{ Serum $\beta 2 M$} \\
\hline Correlation coefficient & 0.999 & 0.940 & 0.944 \\
\hline \multicolumn{4}{|l|}{ Spent dialysate $\beta 2 \mathrm{M}$} \\
\hline Correlation coefficient & Not measurable & 0.971 & Not evaluable \\
\hline Regression equation & Not measurable & $\mathrm{Y}=90.7 \mathrm{e}^{-0.0041}$ & Not evaluable \\
\hline Regression equation & $\mathrm{Y}=98.9 \mathrm{e}^{-0.0042 \mathrm{X}}$ & $\mathrm{Y}=95.0 \mathrm{e}^{-0.005 \mathrm{X}}$ & $\mathrm{Y}=89.9 \mathrm{e}^{-0.0053 \mathrm{X}}$ \\
\hline \multicolumn{4}{|c|}{ Spent dialysate emission $340 \mathrm{~nm}$} \\
\hline Correlation coefficient & 0.989 & 0.979 & 0.979 \\
\hline Regression equation & $\mathrm{Y}=98.8 \mathrm{e}^{-0.0019 \mathrm{X}}$ & $\mathrm{Y}=95.1 \mathrm{e}^{-0.0027 \mathrm{X}}$ & $\mathrm{Y}=95.1 \mathrm{e}^{-0.0027}$ \\
\hline
\end{tabular}


of $\beta 2 \mathrm{M}$ in spent dialysate. Moreover, the time courses of UV absorption and fluorescence emission of spent dialysate during dialyses with HF-ADS membrane were completely independent from that of $\beta 2 \mathrm{M}$ measured with biochemical methods. The fluorescence emission is possibly determined by naturally fluorescent compounds [7] or by other molecules still unknown. In addition, our data indicate that even biochemical determinations in spent dialysate cannot be used to monitor the plasma disappear- ance of substances mainly removed by adsorption to dialysis membrane, like $\beta 2 \mathrm{M}[8]$.

We conclude that the removal of $\beta 2 \mathrm{M}$ cannot be evaluated by spectrophotometric analysis of spent dialysate.

\section{Disclosure Statement}

The authors declare nothing to disclose.

\section{References}

1 Daugirdas JT: Second generation logarithmic estimates of single-pool variable volume $\mathrm{Kt} / \mathrm{V}$ : an analysis of error. J Am Soc Nephrol 1993;4:1205-1213.

2 Fridolin I, Lindberg LG: On-line monitoring of solutes in dialysate using wavelengthdependent absorption of ultraviolet radiation. Med Biol Eng Comput 2003;41:263270.

3 Uhlin F, Fridolin I, Lindberg LG, Magnusson M: Estimation of delivered dialysis dose by on-line monitoring of the ultraviolet absorbance in the spent dialysate. Am J Kidney Dis 2003;41:1026-1036.
4 Castellarnau A, Werner M, Günthner R, Jakob $\mathrm{M}$ : Real-time Kt/V determination by ultraviolet absorbance in spent dialysate: technique validation. Kidney Int 2010;78:920-925.

5 Donadio C, Calia D, Ghimenti S, Onor M, Colombini E, Fuoco R, Di Francesco F: Uric acid is the major determinant of absorbance in spent dialysate allowing spectrophotometric evaluation of dialysis dose. J Nephrol 2014; 27:331-337.

6 Vanholder R, De Smet R, Glorieux G, Argilés A, Baurmeister U, Brunet P, Clark W, Cohen G, De Deyn PP, Deppisch R, Descamps-Latscha B, Henle T, Jörres A, Lemke HD, Massy
ZA, Passlick-Deetjen J, Rodriguez M, Stegmayr B, Stenvinkel P, Tetta C, Wanner C, Zidek W: Review on uremic toxins: classification, concentration, and interindividual variability. Kidney Int 2003;63:1934-1943.

7 Swan JS, Kragten EY, Veening H: Liquidchromatographic study of fluorescent materials in uremic fluids. Clin Chem 1983;29: 1082-1084.

8 Randoux C, Gillery P, Georges N, Lavaud S, Chanard J: Filtration of native and glycated beta2-microglobulin by charged and neutral dialysis membranes. Kidney Int 2001;60: 1571-1577. 